\title{
A Model Performance Standard for Guardrails
}

S. G. Fattal, L. E. Cattaneo,

G. E. Turner, and S. N. Robinson

Center for Building Technology Institute for Applied Technology National Bureau of Standards

Washington, D. C. 20234

July, 1976

Final Report

"This report is to be incorporated as an appendix in a future publication which will receive general distribution. Please consult the National Bureau of Standards Office of Technical Publications to obtain the proper citation."

Prepared for

ccupational Safety and Health Administration )epartment of Labor Vashington, D. C. 20210

.456 
,

\section{A MODEL PERFORMANCE STANDARD FOR GUARDRAILS}

S. G. Fattal, L. E. Cattaneo,

G. E. Turner, and S. N. Robinson

Center for Building Technology Institute for Applied Technology

National Bureau of Standards

Washington, D. C. 20234

July, 1976

Final Report

"This report is to be incorporated as an appendix in a future publication which will receive general distribution. Please consult the National Bureau of Standards Office of Technical Publications to obtain the proper citation."

Prepared for

Occupational Safety and Health Administration

Department of Labor

Washington, D. C. 20210

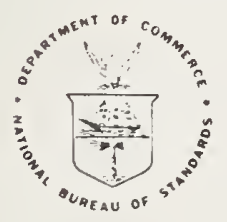

U.S. DEPARTMENT OF COMMERCE, Elliot L. Richardson, Secretary Edward O. Vetter, Under Secretary

Dr. Betsy Ancker-Johnson, Assistant Secretary for Science and Technology

NATIONAL BUREAU OF STANDARDS, Ernest Ambler, Acting Director 
Abstract . . . . . . . . . . . . . . . . . . . . . . . . . . 11

A.1 Introduction . . . . . . . . . . . . . . . . . . . . . . . . 1

A.2 Structural Safety. . . . . . . . . . . . . . . . . . . . . 3

A.2.1 Basic Loads. . . . . . . . . . . . . . . . . . . . 3

A.2.2 Design Loads . . . . . . . . . . . . . . . . . . . . 6

A.2.3 Structural Resistance. . . . . . . . . . . . . . . . 8

A.2.4 Foundations . . . . . . . . . . . . . . . . . . 12

A.2.5 Displacement Control . . . . . . . . . . . . . . . . . . 13

A.2.6 Durability and Maintenance . . . . . . . . . . . . . . . . 13

A.3 Non-structural Safety. . . . . . . . . . . . . . . . . . . . . . 14

A.3.1 Height of Guardrail. . . . . . . . . . . . . . . . . 14

A.3.2 Height in Relation to Width. . . . . . . . . . . . . . . . . 16

A.3.3 Size of Openings . . . . . . . . . . . . . . . . . 17

A.3.4 Passage of Objects Near Floor. . . . . . . . . . . . . . . 18

A.3.5 Smoothness of Surfaces . . . . . . . . . . . . . . . 18

A.3.6 Projecting Components. . . . . . . . . . . . . . . . . . 19

A.3.7 Visibility . . . . . . . . . . . . . . . . . 19

A.3.8 Warning Signs. . . . . . . . . . . . . . . . . . . 20

A.4 Definitions. . . . . . . . . . . . . . . . . . . . . . . . 21

A.5 References . . . . . . . . . . . . . . . . . . . . . . 22

B.1 Examples of Standard Guardra11 Designs . . . . . . . . . . . . . . . . . 23 
A MODEL PERFORMANCE STANDARD FOR GUARDRAILS

S. G. Fattal, L. E. Cattaneo

G. E. Turner and S. N. Robinson

\begin{abstract}
A model performance standard and design illustrations are presented for the design, construction and evaluation of guardrail systems, which will be used for the protection of employees against occupational hazards. The standard stipulates both structural and non-structural safety requirements. Each criterion includes a commentary section describing the rationale used in its formulation. This rationale is for the most part, based on independent experimental and analytical research investigations conducted at NBS in behalf of OSHA.
\end{abstract}

Key Words: Design; dynamic loads; guardrails; industrial accidents; non-structural safety; occupational hazards; performance standard; personnel railings; personnel safety; static loads; stiffness; structural safety.

\title{
Acknowledgement
}

The contributions made by Drs. Robert A. Crist and Bruce R. Ellingwood in critically reviewing this Standard are gratefully acknowledged. 
A Model Performance Standard

for Guardrails

\section{A.1 Introduction}

This Standard documents recommendations for the design, construction and evaluation of guardrail systems which are installed for the purpose of protecting employees from occupational hazards during the conduct of their assigned tasks. The document makes no recommendations as to where or whether guardrails will be required, and is not applicable to situations where the guardrail may be exposed to forces resulting from the impact of power-driven objects or from flagrant abuse.

For the most part, these recommendations draw upon the results of tests and analytical investigations conducted at the National Bureau of Standards (NBS) in behalf of the Occupational Safety and Health Administration (OSHA) and documented in detail in a separate report.* Where a specific recommendation is based on studies conducted elsewhere, the standard identifies the appropriate source in the bibliography $* *$ in Section A.5.

The performance approach usually permits the definition of a particular performance attribute without reference to the type of material or construction scheme employed. It is generally less restrictive than materials-oriented prescriptive standards with regard to the utilization of innovative products and design concepts. The terms "conventional" and "non-conventional" have been introduced to distinguish, when necessary, between traditional and innovative applications. Conventional systems or components are built with traditional construction materials (such as steel, aluminum, concrete, masonry and timber), which are deployed in the system in a manner that will constitute a conventional design and construction concept or application. Non-conventional systems or components consist of relatively untried materials or any other materials which are utilized in a manner that aould constitute an innovative construction or design concept.

Unless otherwise noted, these recommendations apply to both conventional and nonconventional systems. Conventional systems should, in addition, comply with the appropriate design and construction requirements of the six nationally recognized standards [A.3 - A.8] adopted herein by reference. These standards were judged to have adequate provisions to permit the design of conventional guardrails without the need to prescribe supplementary requirements.

"This report to be entitled "Investigation of Guardrails for the Pr stection of Employees from Occupational Hazards," by S. G. Fattal, and L. E. Cattaneo, is (as of July 1976) in the final stages of preparation.

**References are indicated by numbers in brackets. 
A guardrail system is defined herein as a structural system which is designed and installed in a manner that will Inhibit accidental passage of people or objects between the two adjoining regions if separates in the interest of improving the safety of the environment. Guardrails are distinguished from handrails in that handrails are normally installed for the purpose of assisting people in maintaining balance while in the act of walking, climbing and descending stairs, etc. However, in situations where handrails serve the function of guardrails, such as when located along the precipitous edge of a stairway or around elevated landings, they should be designed as guardrails. This Standard includes provisions for the design of guardralls which are specifically called upon to support people or objects during the conduct of an activity. Additional design load requirements are specified for guardrails installed at or near areas where congested peak loading conditions are likely to be encountered in service.

Guardrail systems consist of elements, connections and anchorages. They encompass both temporary and permanent installation. Temporary guardrail systems are used in construction work. Permanent guardrail systems constitute a permanent part of a structure in service. Unless stated otherwise, the provisions of this standard apply to temporary as well as permanent guardrails.

The organization of this document is modeled after a fixed format consisting of Requirement, Criterion, Evaluation and Commentary ranked in that order. The Requirement is a qualitative statement of an expected performance attribute. It is a general statement of what the assembly should be able to do. The Criterion is a quantitative statement giving the level of performance necessary to meet the Requirement. In some cases, several Criteria are associated with each requirement. Evaluation sets forth the method(s) upon which an evaluative judgment of compliance with a Criterion can be based. It states the standards, contract documents, inspection methods, analysis and review procedures, or test methods which may be used in determining whether the system or system components comply with the Criterion. The Commentary provides background information for the reader and presents the rationale behind the Requirement, Criterion and Evaluation.

The Criteria in this standard are identified with one of two categories, namely, structural and non-structura1. The structural Criteria specify the types of loads and load combinations to be considered in design, and resistance requirements with regard to strength, safety margins, stiffness properties and deformation tolerances in service. The nonstructural Criteria pertain to the geometric configuration of guardrails as governed by the topography and physical characteristics of the surrounding environment and the relationships between perceptual and environmental factors. 


\section{A.2 Requirement - Structural safety}

Guardrails and all components thereof shall be designed and constructed to support safely all loads anticipated in service.

\section{A.2.1 Criterion - Basic loads}

Design loads shall be derived from the following basic loads and their combinations:

(a) Dead load (D) shall consist of the actual weight of the materials incorporated in the construction and the weight of any appendage or attachment which becomes a permanent part of the guardrail system in service.

(b) Accidental load (A) shall consist of a concentrated force of $300 \mathrm{lb}$ (1.335 kN) for tributary areas $36 \mathrm{in}(91.5 \mathrm{~cm})$ or greater in width, and $200 \mathrm{lb}(0.890 \mathrm{kN})$ fur tributary areas 24 in $(61 \mathrm{~cm}$ ) or less in width. For tributary areas between 24 in (61 cm) and 36 in $(91.5 \mathrm{~cm})$ in width, the concentrated force shall be determined by linear interpolation.

When combined with other basic loads in accordance with Criterion A.2.2, the point of application and direction of accidental load (A) shall be so determined as to produce the most critical configuration(s) for design.

For calculating local effects, the concentrated force representing accidental load (A) may be uniformly distributed over a $4-i n$ (10.2-cm) length of a beam element or over a $16-i n^{2}\left(103 \cdot 2-\mathrm{cm}^{2}\right)$ square area of a plate element.

(c) Surge load (S) shall consist of a uniformly distributed of $100 \mathrm{lb} / \mathrm{ft}$ $(1.46 \mathrm{kN} / \mathrm{m})$ applicable to the top of the guardrail at any inclination between and including horizontal and vertical, subject to the following constraints:

(d) Live load (L) shall consist of any load for whin the guardrail is anticipated to provide the eeans of structural support in service other than dead, accidental or surge load. 


\section{A.2.1.1 Evaluation}

This Criterion will be evaluated by review of the contract documents (plans, specifications and structural calculations). Ihe. width of the tributary area will be measused horizontally as illustrated in figure A.2. A.2.1.2 Commentary

This criterion defines the nature and intensity of basic load types, combinations of which are specified for design. It is not the intent of this Criterion to include provisions for abnormal loads or loads resulting from flagrant abuse. Abnormal loads may be attributable to a rare but extreme event such as an explosion or impact by power-driven objects, while deliberate acts such as climbing or bouncing against the guardrail are construed as instances of flagrant abuse.

Unlike larger structures, the weight of the materials comprising the guardrail system will probably be small enough to be negligible in design. However, in some instances it could conceivably increase the calculated stresses by 10 per cent or more and the inclusion of dead load (D) in this Criterion is intended to serve as a reminder that it should not be routinely ignored or overlooked in design. Dead load should include the weight of any object which will become a permanent part of the guardrail in service. The weight of any temporary attachment should be treated as part of the live load (L).

Accidental load (A) represents a force transmitted by the accidental impact of human subjects or objects against guardrails. The 300-1b (1.335-kN) intensity is derived from the results of dynamic load tests using anthropomorphic dumies falling backward against an instrumented muck-up rail from a standing position. The height of the rail and the initial distance of the dummy from it were varied during the tests tc measure the influence of these parameters on the magnitude ot the impact load. It was otserved, for instance, that the miximum load on the midrail was not substantially different frum that obtained from top rail tests. This partly explains the rationale for prescribing the same concentrated load at locations other than the top of the guardrail as well. In addition, the Criterion recognizes the need to provide a minimum level of structural resistance against loads resulting from the accidental impact of rolling or sliding objects, or any 
equipment other than power-driven objects which may accidentally come in contact with the guardrail. It has been implicitly assumed that the magnitude of such loads would not be appreciably greater than those transmitted by accidental falls of human subjects.

The gradual reduction of the $300-1 b(1335-N)$ force to $2001 \mathrm{~b}$ ( $890 \mathrm{~N})$ with the width of the tributary area varying from $36 \mathrm{in}(91.5 \mathrm{~cm})$ to 24 in (61 cm) is consistent with the experimentally observed force reduction for falls from an initial heel distance less than $30 \mathrm{in}(76.2 \mathrm{~cm})$. In this regard it is assumed that for a given width of tributary area, the maximum possible distance from which the subject can fall on the rail is about 6 in $(15.3 \mathrm{~cm})$ less than the width of that area.

No constraints are placed as to the direction of load (A) other than those which can be definitely eliminated by virtue of special characteristics of the environment. For instance, a guardrail without openings, installed to prevent accidental movement from area one into area two, will be subjected to accidental loads from one side only. Where guardrail openings are large enough to permit accidental wedging of humans or objects, forces of unknown intensity will be induced, and thus prudent design practice would select components to have a minimum level of resistance (usually 40 percent of maximum design resistance) in the weakest plane.

Provision A.2.1 (b) makes an allowance for the capacity of the human body to distribute the impact force over a finite length or area which, according to test observations, generally exceeds the specified values when the impact force is in the neighborhood of $300 \mathrm{lb}(1.335 \mathrm{kN})$ or greater. This information is utilized in design to check sectional adequacy (i.e., shear crippling, bearing capacity, local stability etc.) in the vicinity of the applied force.

The provision for surge load (S) recognizes the need to mitigate structural failures under the action of a group of people pushing against the guardrail. Conditions for surge loading could develop as a result of a large number of people simultaneously seeking passage through an exitway or gangway. The $100-1 \mathrm{~b} / \mathrm{ft}(1.46-\mathrm{kN} / \mathrm{m})$ uniform load intensity is based on experiments involving measurements of loads transmitted by a group of human subjects, three deep, pushing against an instrumented mock-up guardrail. The mean weight of the subjects selected for this experiment was approximately representative of the weight of the 50 percentile adult male population of the United States.

Live load (L) accounts for a wide variety of imposed loads which the guardrail may be called upon to resist during its service life other than those resulting from surge (S) or accidental impact (A). It is neither feasible nor necessary to identify precisely all the possible loads belonging to this category within the scope of this Criterion. It is possible, however, to identify a given live load with one of two categories: The first category 
includes all live loads associated with a specific use or activity for which the guardrail must provide structural support in service. In some cases, the intended structural function of the guardrail includes providing the means of support for workers and/or equipment during the routine conduct of work-related tasks. Specific instances are guardrails used as a bench, or as a lifeline, or for the support of workers and equipment in a tree-spraying cperation. The second category includes all live loads which might be anticipated to occur in service as a result of human-environmental factors (other than flagrant abuse) which may generally be construed as guardrail misuse. The source of such imposed loads mav nut be readily obvious at the design stage. For instance, a guardrail may be exposed to a crowd leaning over it to watch an interesting event several stories below, or it may receive loads from people sitting on a nearby bench and leaning on it. Likewise, a midrail may invite several people to prop a foot or sit on it. Nevertheless, in most instances it is possible for the designer to identify the nature of such imposed loads through consideration of the relevant human. and environmental factors inherent to the specific installation. uidance on the intensities of certain types of imposed loads may be obtained from the experimental results presented in the NBS report to OSHA.*

This Criterion does not advocate the explicit treatment of wind load as a basic load in guardrail design for a number of reasons. It is noted that both accidental load (A) and surge load (S) are peak loads of very short duration and are not likely to occur frequently in service. The probability of wind occurring at the same time and acting in the same dilection as one of these loads is so low that it may be disregarded justifiably in design. Furthermore, the combination of wind and dead load alone is not likely to be more critical than the design loads prescribed in Criterion A.2.2, nor are the potential consequences of failure (i.e., risk of injury to workers) under such a combination likely to be as severe as those resulting from failures under the design loads specified by Criterion A.2 2. Nonetheless, it is not the intent of this Criterion to rule out consideration of wind effects in design under unusual circumstances. To cite an example, it is conceivable that a group of people leaning over a guardrail at the edge of an elevated exterior platform may experience and transmit signficant wind forces to the guardrail. Such wind-induced forces can be given consideration in design by treating them as part of the basic live load ( $L$ ) defined in this Criterion. The designer may use engineering judgment to select wind pressures consistent with the type and duration of the anticipated live load. Usually checking for wind in regions experiencing 10-psf $\left(479-\mathrm{N} / \mathrm{m}^{2}\right)$ or greater wind pressure is a good engineering design practice. In most instances, the wind load provisions of ANSI A58.1[A.1] used in conjunction with the 2-year wind map in reference [A.2] would probably be adequate.

\section{A.2.2 Criterion - Design Loads}

The following basic load combinations shall be considered in the analysis and design of guardrail systems. These basic loads shall exclude all loads resulting from power-driven objects or from flagrant abuse.

*See footnote on page 1 . 
(a) All guardrails shall be designed for load combination It defined by the folluwin relationship:

$$
U=c_{1} D+c_{2} A
$$

where D and A are basic loads defined under Criterion A.2.1 and the subscripted letters are load factors specified as follows:

(1) For conventional systems designed in accordance with the working stress (or allowable stress) concept, $c_{1}=c_{2}=1.0$.

(2) For conventional systems designed in accordance with the ultimate strength concept, $c_{1}$ and $c_{2}$ shall be the load factors specified by the applicable code. or standard for the load combination $U$ herein defined. The applicable codes and standards are specified in Criterion A.2.3 (a).

(3) For non-conventional systems, $c_{1}=1.4, c_{2}=1.7$.

(b) Guardrails installed at or near exitways serving the function of providing the safe and only means of discharge ur egress of a tributary population equal to o. in excess of 50 persons, shall be designed for the following load combination.

$$
\mathrm{U}=\mathrm{C}_{1} \mathrm{D}+\mathrm{C}_{2} \mathrm{~S}
$$

where D and S are basic loads defined under Criterion A.2.1 and load factors $c_{1}$ and $c_{2}$ are as specified in Criterion A.2.2(a).

(c) Guardrails used as the means of support of workers and/or objects during the conduct of a work task or any other activity not construed as flagrant abuse shall be designed for the following load combination

$$
\mathrm{U}=\mathrm{c}_{1} \mathrm{D}+\mathrm{c}_{2} \mathrm{~L}
$$

where D and L are basic loads defined in Criterion A.2.1 and load factors $c_{1}$ and $c_{2}$ are as specified in Criterion A.2.2(a). Live load L need not include loads resulting from misuse if the guardrail is designed to meet Criterion A.3.7.

\section{A.2.2.1 Evaluation}

This Criterion will be evaluated by examination and review of the contract d. isments. 
Criterion A.2.2 states design load requirements for guardrails. Requirement A.2.2(a) applies to the design of all guardrails while requirements A.2.2(b) and A.2.2(c) apply to guardrails subjected to surge and live loads, rispectively.

Most guardrails will probably need only be designed for load combination A.2.2(a). In the interest of clarity, it should be noted that guardrails required to be designed for more than one loading combination should simultaneously satisfy the design requirements for each loading combination applied independent 1 .

For conventional systems, load factors, $\iota_{1}$. and $c_{2}$ arc introduced lo arrive at design loads which would be consistent with the design approach used by the applicable code or standard. Far instance, components designed in accordance with the allowable stress approach would be proportioned to resist the applicable design load of Criterion A.2.2, with the load factors equal to unity, without developing a maximum stress in excess of the allowable stress prescribed by the governing code or standard. On the other hand, a reinforced concrete element which is designed according to the ultimate strength approach prescribed by the ACI Code [A.5] would be proportioned to have a load-carrying capacity (specified by that Code) equal to or greater than the factored total load on the element specified in Criterion A.2.2, with the load factors $c_{1}=1.4$ and $c_{2}=1.7$ (also specified by that Code).

The Criterion requires that all non-conventional systems be designed by the ultimate strength concept. Accordingly, A.2.2(a)(3) prescribes the magnitudes of the load factors iw be used in design. The specified dead and Live Load factors are consistent with those uscd in conventional design.

J.t should be noted that Criterion A.2.2(c) does not require consideration of loads resulting from misuse as part of live load(L) if criterion A.3.7 is complied with.

\section{A.2.3 Criterion - Structural resistance}

The design load resistance $R$ of the system or any components thereof shall excet the appropriate design load stipulated in Criterion A.2.2, or

$$
\mathrm{R}>\mathrm{U}
$$

Where $U$ is the design load specified by Criterion A.2.2.

(a) For conventioual guardrail systems, the design load resistance $\mathrm{R}$ shall be determined in accurdance with the applicable provisions of the latest editions of the following codes and standards:

(1) Stee1: Manual of Steel Construction, American Institute of Steel Construction $[A .3]$. 
(2) Aluminum: Aluminum Construction Manual, Specifications for Aluminum Structures. the Aluminum Association [A.4].

(3) Concrete: ACI Standard 318-71, Building Code Requirements for Reinforced Concrete, American Concrete Insititute [A.5].

(4) Masonry: Building Code Requirements for Masonry, ANSI A41.1 [A.6] and Building Code Requirements for Reinforced Masonry, ANSI A41.2 [A.7].

(5) Lumber: National Design Specification for Stress-Grade Lumber and Its Fastenings, National Forest Products Association [A.8].

(i) For non-conventional guardrail systems, the design load resistance $\mathrm{R}$ shall be derived from the mean load capacity $\mathrm{R}_{\mathrm{m}}$ as follows:

$$
\mathrm{R}=\mathrm{fR} \mathrm{Rn}_{\mathrm{m}} \mathrm{c}
$$

where:

$f=$ variability factor which should be such that approximately 95 percent of the system as a whole, or any component thereof, shall exceed $f R_{m}$ in resistance. If this resistance has a normal probability distribution, $f=1-1.65 \mathrm{v}$.

$v=$ coefficient of variation of resistance with respect to $R_{m}$.

$c_{u}=$ coefficient for ductility $=(u+7) / 12$, but not more than 1.0

$\mathrm{u}=$ minimum ductility factor under the appropriate design loading condition U defined in Criterion A.2.2.

\section{A.2.3.1 Evaluation}

For conventional systems, design compliance will be evaluated by review of contract documents. Construction compliance will be evaluated by field inspection and comparison of construction with the plans and specifications of the contract documents.

When adequate existing test data on the various material properties comprising the non-conventional system and system components are available, evaluation shall be performed using engineering analysis. When adequate test data is unavailable, system components and subsystems shall be evaluated in the laboratory using simulated static load levels consisterı with the load combinations specified in Criterion A.2.2.

The ductility factor shall be evaluated as follows: For an ideal elastoplastic (elastic-perfectly plastic) resistance function (plot of applied load as ordinate and deflection as abscissa), the ductility factor is defined as the ratio of ultimate deflection tc yield deflection ( $\mathrm{u}=\mathrm{d}_{\mathrm{u}} / \mathrm{d}_{\mathrm{ye}}$ ). For a linear resistance function to failure (brittle behavior), the ductility factor is 1.0. For an actual (nonlinear) load-deflection function, 
the ductility factor shall be computed from an "effective" function consisting of two strajglit lines (Figure A.1). The first line is drawn through the origin and a point on the actual function at which the resistance is 60 percent of its maximum load value $\left(\mathrm{P}_{\mathrm{u}}\right)$. The second line is a horizontal line ending at the ultimate deflection $\left(d_{u}\right)$, which is the abscissa of a point on the descending portion of the resistance function with the corresponding ordinate equal to 95 percent of the maximum load value. The horizontal line is located so that the area under the two lines forming the effective function is equal to the area under the actual function up to the point of ultimate deflection. Effective yield deflection (dye) is taken as the deflection at the point of intersection of the two lines, which is at a resistance level termed "effective yield resistance." The ductility factor is based on the effective resistance function: $u=d_{u} / d_{y e}[A .9]$.

\section{A.2.3.2 Commentary}

The intent of Criterion A.2.3(a) is to require, to the extent possible, design and construction compliance with the provisions of nationally recognized codes and standards. Accordingly, Criterion A.2.3(a) gives a specific list of voluntary consensus standards which are judged to be applicable to conventional guardrail systems. The requirements of these standards should be used in conjunction with the design loads stipulated in Criterion A.2.2 and with the provisions of all the other criteria applicable to conventional systems. As a general guide, guardrail systems using structural steel, aluminum, timber, reinforced concrete or masonry do not need overall margins of safety greater than those found in structures designed in accordance with the design standards listed under Criterion A.2.3(a).

The intent of Criterion A.2.3(b), along with Criterion A.2.2, is to provide a minimum level of structural safety against situations which might be anticipated to occur during the service life of the system. The safety margin reflects possible sources of deficiencies such as variations in loading and resistance, as well as assumptions and simplifications made in analysis and design.

The load capacity is reduced from the mean strength value $R_{m}$ using variability factor $\mathrm{f}$ to insure that approximately 95 percent of all systems or components thereof will have at least the required load capacity. The reduction provides for the combined effect of variability in material strength, workmanship, dimensions and quality control.

For relatively untried materials and construction concepts, a reasonable allowance must be made for lack of experience relative to structural response and for variability in material strength. It should be recognized that certain structural materials require a greater margin of safety than others because of either the more critical nature of failure or the greater variability in their strength. 


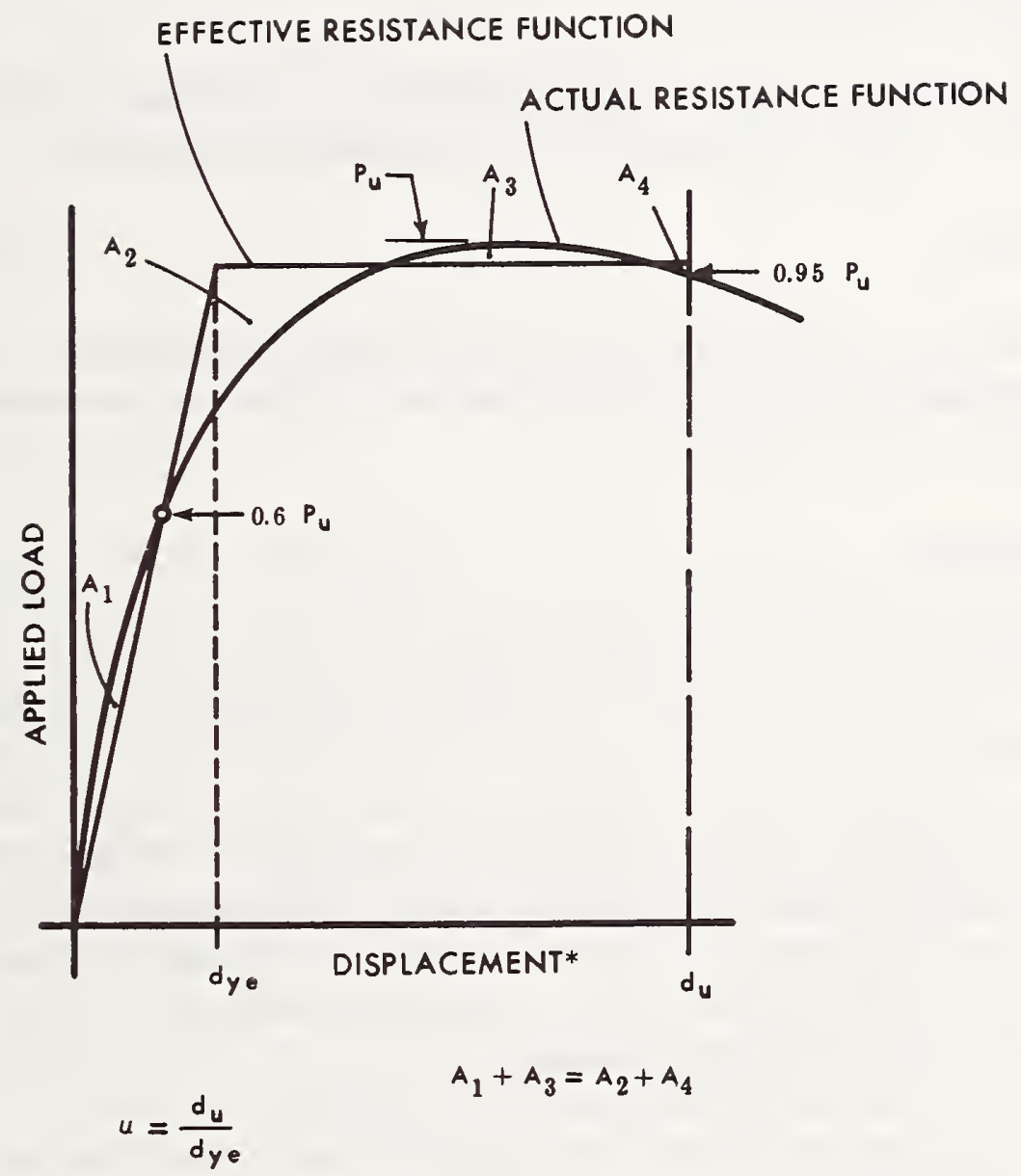

(* Distortional displacement at and in the direction of applied load)

Figure A.1 Determination of the Ductility-Factor 
Ductility as well as strength is vital to safety. Adequate ductility allows energy absorption under extreme dynamic or pulse loads, permits redistribution of local concentrations of force from fabrication errors, lack of construction fit or local loadings, and by perceptible inelastic deformations warns users of overloads before load capacity is lost. The coefficient for ductility $c_{u}=(u+7) / 12$ imposes an extra margin of strength for brittle materials, and becomes 1 at $u=5$, which is considered representative of ductile structural systems.

\section{A.2.4 Criterion - Foundations}

Foundations shall provide the means for attachment of guardrail systems and shall be designed to safely transmit guardrail loads to the supporting structure.

\section{A.2.4.1 Evaluation}

The adequacy of the foundation will be determined by inspection and review of contract documents of the supporting structure including details of anchoring devices used for attachment of guardrail to the structure.

\section{A.2.4.2 Commentary}

This Criterion provides for the safe support of the guardrail system by the part of the structure to which it is attached. Foundation failures might affect the stability of the entire guardrail system and therefore can be potentially more hazardous in nature than the failure of a single element or connection. A case in point is the premature failures observed in concrete skirts supporting peripheral guardrails at elevated stairway landings attributable to several factors such as insufficient edge distance, shallow embedment of posts and anchors or inadequate reinforcement. The intent of the criterion is to design the supporting foundation to be at least as safe as the guardrail system and thereby reasonably assure against premature failures.

This Criterion also addresses a frequent problem which arises from the inability, on the part of the contractor, to attach guardrails to an otherwise adequate foundation to retrofit sections of a completed structure without exposing his employees to additional risk. This situation is encountered most commonly during the installation of temporary guardrails needed for construction or repair work and there have been instances where the potential risk of accident associated with the erection and removal of such guardrails could not be construed to be less than the risk of accidents attributable to the absence of a guardrail. This criterion therefore stipulates that foundations should be designed and constructed in a manner that would provide a practical and expedient means for the subsequent attachment of guardrails where required by law. 


\section{A.2.5 Criterion - Displacement control}

Non-conventional systems shall comply with this Criterion. Conventional systems are deemed to satisfy this Criterion.

(a) With the full dead load 1.OD in place, the maximum displacement of any point on the guardrail due to the applied load of $1.5 \mathrm{~A}$ sustained for one hour, shall not exceed 4 in $(10.16 \mathrm{~cm})$.

(b) With the full dead load 1.OD in place, the maximum vertical sag of any flexurally nonrigid element as installed shall not exceed 2 in $(5.08 \mathrm{~cm})$.

\section{A.2.5.1 Evaluation}

Criterion A.2.5 (a) will be evaluated by the physical simulation and laboratory testing of a suitable component or assembly of the system and/or by analysis based on performance data or available test data.

Criterion A.2.5 (b) will be evaluated in the field. The sag is the vertical distance between an imaginary straight line joining the two support points and the lowest point on the element.

\section{A.2.5.2 Commentary}

This Criterion introduces displacement limitations deemed necessary to reduce the likelihood of accidental passage of human subject and/or objects over or through the guardrail. Flexible cables such as wire rope will probably need to be maintained under a minimum level of tension in order to comply with Criterion A.2.5 (a). On the other hand, a certain amount of permanent sag may be tolerated in the case of chains which are quite stiff axially once they become taut. It should be noted that any element having the 2-in sag allowed by Criterion A.2.5 (b) will need to have a relatively high axial stiffness in order to meet the displacement limitation of Criterion A.2.5 (a) because the displacement attributable to sag will reduce the permissible displacement due to structural deformation. Additionally, Criterion A.2.5 inhibits the use of non-conventional products exhibiting excessively high creep deformations or low modulus of elasticity which makes them unsuitable for structural applications.

\section{A.2.6 Criterion - Durability and maintenance}

(a) Guardrails exposed to the exterior environment or to chemicals and other corrosive agents and conditions shall be adequately treated to resist the effect of such agents in service. 
(b) Guardrails shall be periodically inspected for evidence of excessive wear, damage or understrength. Any element, connection or anchorage exhibiting 20 percent or more degradation in strength and/or stiffness shall be replaced or restored to its initial condition.

\section{A.2.6.1 Evaluation}

Durability characteristics and required maintenance will be determined by field inspection and/or testing and engineering analysis. Loss of stiffness can be evaluated in the field by measuring the deflection produced under a given load and comparing it with the deflection of new replicates tested in the laboratory, or, if sufficient test data are available, deflections from field tests may be compared with calculated deflections based on known material properties.

In the absence of an adequate field test method to measure strength degradation, it may be assumed that loss of strength is proportional to loss of stiffness.

\section{A.2.6.2 Commentary}

The intent of this Criterion is to insure that a minimum level of structural integrity is maintained during service. In many instances it is possible to identify damage such as dents, cuts, splits, bends, rust, abrasions, etc., by means of visual inspection. Slight shaking of the rail with the hand may reveal slack in the system and help identify loose connections or anchorages.

\section{A.3 Requirement - Non-structural safety}

A guardrail system separating two adjoining regions shall prevent and control the accidental passage of workers and objects from one region into the other.

\section{A.3.1 Criterion - Height of guardrail}

Except as permitted by Criterion A.3.2, the minimum height $\mathrm{H}$ of the guardrail system relative to the adjacent floor or walking surface shall be 42 in $(106.68 \mathrm{~cm})$ except if the top rail is flexurally non-rigid $\mathrm{H}$ shall be 44 in $(111.76 \mathrm{~cm}$ ).

\section{A.3.1.1 Evaluation}

Height $\mathrm{H}$ will be measured within a tolerance of 1 in $(2.54 \mathrm{~cm})$ in the direction normal to the adjacent floor or walking surface as defined in figure A.2. Where any object large enough to be stood over is located on the floor adjacent to the guardrail, or where a layer of debris has accumulated on the floor adjacent to the guardrail, the effective height $\mathrm{H}$ will be measured relative to the top of such object or layer. 

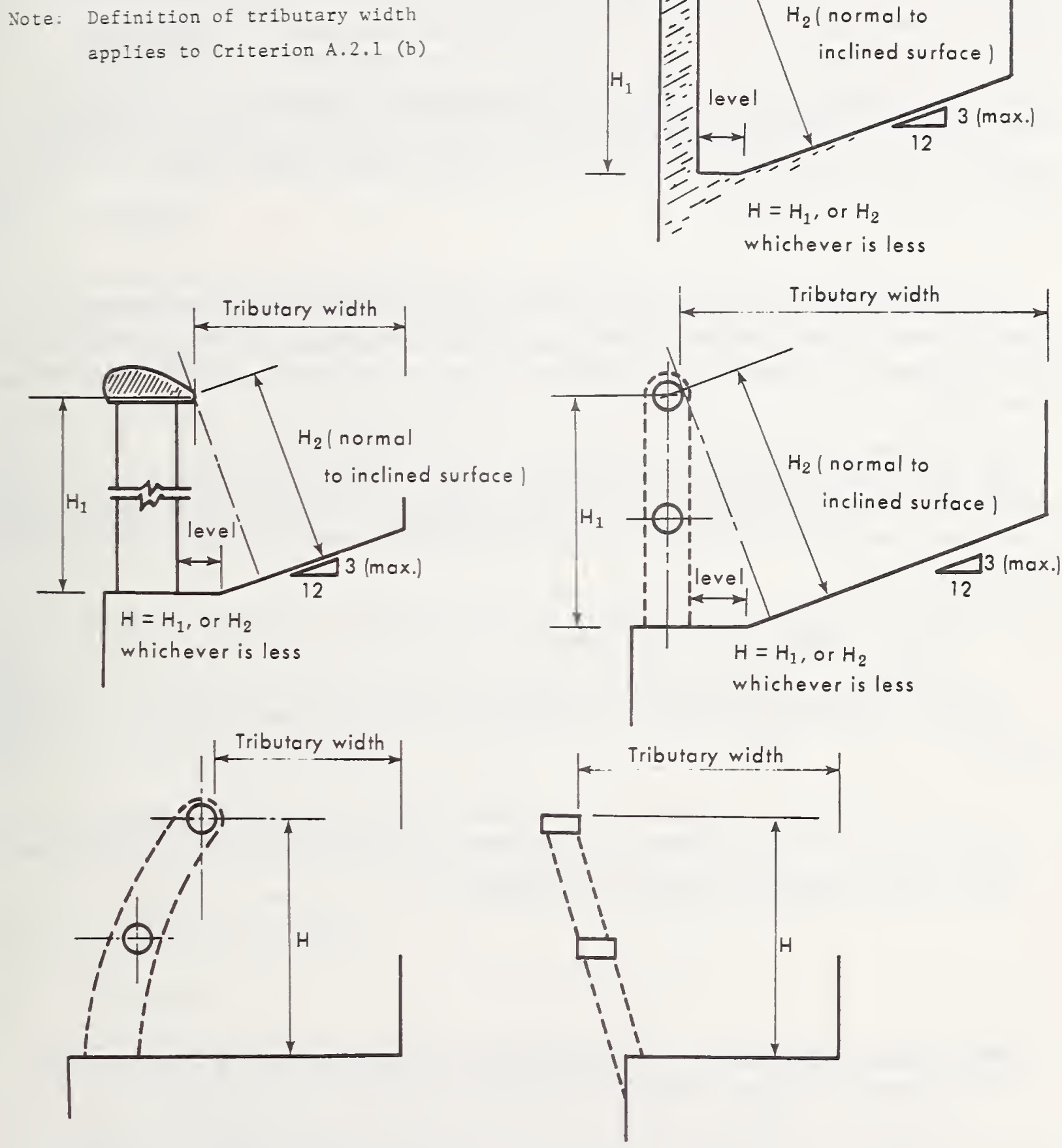

Figure A.2 Definition of guardrail height $\mathrm{H}$ 


\section{A.3.1.2 Commentary}

The rationale for the height requirement is to inhibit accidental passage of the human body over the guardrail. The prescribed height of the guardrail system is set approximately equal to the height of the centroid of the 95 percentile composite adult male population in the United States [A.10]. The centroidal height of the subject is measured with the subject in a straight posture standing on a level surface. Tests using anthropomorphic dummies and mock-up guardrails have indicated that the chances of the dummy going over the guardrail increase rapidly when the top rail is positioned at heights lower than the centroid of the dummy. These tests involved simulation of various postures of human subjects leaning against the guardrail as well as human subjects moving at normal or brisk walking speeds and squarely impacting against the guardrail.

The increased height prescribed for flexurally non-rigid top rails such as tensioned cables or draped chains recognizes the need to compensate for height loss due to generally larger displacement of these elements relative to other top rails under the same anticipated service loads.

The 1-in tolerance specified under section A.3.1.1 is considered necessary to allow for the possible deviation from the prescribed 42-in height that may be anticipated to occur as a result of materials imperfections, settlements, creep, warping and miscellaneous other aging effects.

\section{A.3.2 Criterion - Height in Relation to Width}

The height requirement stipulated in Criterion A.3.1 may be relaxed under the following conditions :

(a) If the top surface of the guardrail is horizontal and has a width greater than 6 in $(15.24 \mathrm{~cm})$, and the floor surface of the interior adjoining region is level, the mininum height $\mathrm{H}$ of the guardrail shall be not less than,

$$
\mathrm{H}=\mathrm{K}_{1}-\mathrm{B}
$$

where $B$ is the minimum width of the top surface of the guardrail and $K_{1}$ is 48 in (121.92 $\mathrm{cm})$. However, in no case shall the minimum height be less than 30 in $(76.2 \mathrm{~cm})$.

(b) If, in addition to the conditions stipulated in (a) above, the projection of any part of the human body beyond the exterior edge of the top surface of the guardrail brings it in contact with a hazardous substance, the minimum width B of the top surface of the guardrail shall be not less than 


$$
\mathrm{B}=\mathrm{K}_{2}-2 \mathrm{C}
$$

where $\mathrm{C}$ is the vertical distance of the boundary of the hazardous region below the exterior edge of the top surface of the guardrail and $\mathrm{K}_{2}$ is 36 in $(91.44 \mathrm{~cm})$. However, in no case shall the minimum width be less than 24 in $(60.96 \mathrm{~cm})$.

\section{A.3.2.1 Evaluation}

Compliance will be determined by measurements and inspection in the field after installation. Height $\mathrm{H}$ and width $\mathrm{B}$ will be evaluated within a tolerance of 1 in $(2.54 \mathrm{~cm})$.

\section{A.3.2.2 Commentary}

The minimum height of 30 in $(76.2 \mathrm{~cm})$ is 9 in $(22.86 \mathrm{~cm})$ above the kneecap height of the 95 percentile adult male subject in the United States, measured from the floor where the subject is in straight standing posture on level surface. The 9-in $(22.86 \mathrm{~cm})$ distance permits the human subject to exercise leverage, assuming adequate ground friction, against overturning following his accidental backing onto the guardrail. In addition, tests have indicated that, at a guardrail height of 30 in $(76.2 \mathrm{~cm})$, the 95 percentile human male subject does not gain reach advantage when he assumes a climbing posture (with one foot on the floor and the other on top of the rail) as opposed to his reach when both his feet are on the floor.

The equation prescribed in Criterion A.3.2 (a) is based on 95 percentile dummy tests which indicate that a height less than 30 in $(76.2 \mathrm{~cm})$ increases the likelihood of total passage to the other side of the guardrail following an accidental fall. The minimum width of $24 \mathrm{in}(60.96 \mathrm{~cm}$ ) stipulated in Criterion A.3.2 (b) is likewise based on the same tests using the 95 percentile dummy .

\section{A.3.3 Criterion - Size of openings}

Any opening in the guardrail system shall reject passage of a spherical object 19 in $(48.3 \mathrm{~cm})$ and greater in diameter.

\section{A.3.3.1 Evaluation}

This Criterion will be evaluated by field measurement after installation using a 19-in $(48.3-\mathrm{cm})$ spherical object. In the case of flexurally non-rigid elements with sag, the object should be forced only to the extent needed to take up the slack or to make such elements taut but without stretching them. 


\section{A.3.3.2 Commentary}

The rationale for this criterion is to inhibit accidental passage of the human body through guardrail openings. The dimension given for the spherical object is slightly more than the shoulder width of the 50 percentile U.S. adult male population [A.10]. In this regard, it is noted that the chest depth for the 5 percentile U.S. male (which is less than the corresponding size of the 5 percentile U.S. female) is approximately 8 in $(20.3 \mathrm{~cm})$. Therefore, it is implicitly assumed that the subject will be capable of grabbing the guardrail or wedging himself by some other means and prevent his complete passage to the exterior after such passage is accidentally initiated.

\section{A.3.4 Criterion - Passage of objects near the floor}

Guardrails shall reject the passage of spherical objects 0.5 in $(1.27 \mathrm{~cm})$ and greater in diameter, up to a height of 5 in $(12.7 \mathrm{~cm})$ from the adjacent floor surface. This Criterion may be waived if it can be satisfactorily established that no risk of injury to personnel arises as a result of said waiver.

\section{A.3.4.1 Evaluation}

This Criterion will be evaluated by field inspection after installation. The 5-in $(12.7-\mathrm{cm})$ height will be measured normal to the adjacent floor surface in a manner similar to measurement of guardrail height (refer to figure A.2).

\section{A.3.4.2 Commentary}

The rationale for this criterion is to prevent the shod foot, hand tools and miscellaneous small debris from falling, sliding or rolling under the guardrail. The 5-in (12.7-cm) minimum height dimension is approximately based on the ankle pivot height of the 95 percentile U.S. male wearing heavy winter footwear [A.10]. It is assumed that this height will be sufficient to prevent passage of hand tools and debris.

The specified waiver is predicated on the condition that no risk of injury to employees exists on either side of the guarded area by virtue of such omission. It is recommended that compliance with this criterion be required for all inclined work surfaces protected by gaurdrails installed on the downhill side, to provide an obstacle against, and thereby inhibit, accidental slippage of subjects under the guardrail. It is likewise recommended that compliance with this criterion be required in all cases where the risk of injury to employees exists as a result of loose objects accidentally leaving the guarded area. 


\section{A.3.5 Criterion - Smoothness of surfaces}

The surfaces and edges of guardrail systems shall be smooth and void of characteristics that can capture clothing or cause cuts, snags, abrasions, or other injuries to the hands and other parts of the body as a person cames in contact with the guardrail while standing or conducting a work activity next to it.

\section{A.3.5.1 Evaluation}

Inspection and/or field testing after installation. Field testing will be conducted using one layer of a wet, commercially avallable chamois skin wrapped around a gloved hand. The chamois skin will be run along surfaces or edges exposed to body contact and observed for substantial cuts, tears, punctures or other major destruction to the surface. Any evidence of such destruction may be interpreted as fallure of compliance with this Criterion.

\section{A.3.5.2 Commentary}

The intent of this criterion is to reduce the potential risk of injury resulting from contact with rough surfaces. To satisfy this Criterion, surfaces should be void of sharp projections (screws, nails, threaded ends of bolts), substantial delaminations having sharp edges or points (cracked wood or metal skins), etc.

Although the field test suggested is rather crude (see reference [ $\dot{A} .11]$ for additional information), it may be used together with visual inspection to provide an indication of relative roughness of surfaces. This test may be rendered more effective by specifying standards for the materials used (chamois skin and glove), the applied force, the contact area and the speed of the movement. For better control, a standard padded object may be used in lieu of the gloved hand.

\section{A.3.6 Criterion - Visibility}

The color or intensity of the guardrail system or the minimum dimension of any guardrail element shall be such that it can be readily seen at any distance from the guardrail up to 25 ft $(762 \mathrm{~cm})$ away. 


\section{A.3.6.1 Evaluation}

This Criterion will be evaluated by analysis or by field inspection if deemed necessary. The minimum required dimension of any guardrail component will be determined according to the viewing distance formula [A.12, A.13]

$$
t=0.0025 d_{v}
$$

where $t$ is the minimum dimension of the guardrail component and $d_{v}$ is the viewing distance.

Field inspection will be conducted during the period when employees are on duty and under adverse environmental conditions (i.e., early morning or late afternoon, overcast skies, time of the year with short daylight, etc.).

\section{A.3.6.2 Commentary}

The intent of this Criterion is to provide for early visual perception of the guardrail and guardrail components (particularly the top rail) by prescribing a safe viewing distance. A commonly accepted value for human reaction time is $3 / 4$ second (driver's handbooks, U.S. Bureau of Public Roads tests on average stopping distance of cars, etc.). The 25-ft (762 cm) distance includes a reaction distance of approximately $10 \mathrm{ft}(304.8 \mathrm{~cm})$ and an assumed stopping distance of $7 \mathrm{ft}(213.36 \mathrm{~cm})$ for a person running at a speed of $10 \mathrm{mph}(16.1 \mathrm{~km} / \mathrm{hr})$. This allows him to stop $8 \mathrm{ft}(243.84 \mathrm{~cm})$ short of the guardrail.

The minimum dimension of guardrail components will probably be greater than 0.75 in $(1.905 \mathrm{~cm})$ when determined by the viewing distance formula in section A.3.7.1, with the exception of wire rope which might have a diameter less than 0.75 in $(1.905 \mathrm{~cm})$ as determined by structural design requirements. In the latter case, this Criterion can be met by attachment of signs of the appropriate size and at such intervals along the element that will make them visible from anywhere within the $25 \mathrm{ft}(762 \mathrm{~cm})$ viewing region.

In instances where the visually handicapped are required to come in contact with the guardrail, or in situations where the task being performed would prevent seeing the guardrail prior to contact with it, acoustic, tactile, and/or other cues should be provided.

\section{A.3.7 Criterion - Warning signs}

Warning signs stating that the guardrail is not to be sat on, stood on, used as a tool, or otherwise misused shall be applied to the guardrail in locations along its length where it is first encountered and at regular intervals elsewhere, and shall be legible at a viewing distance of $10 \mathrm{ft}(305 \mathrm{~cm})$. Guardrails designed to support all loads stipulated in Criterion A.2.2(c) including live loads attributable to misuse need not comply with this Criterion. 


\section{A.3.7.1 Evaluation}

This Criterion will be evaluated by analysis using the viewing distance formula given in section A.3.6.1, and, if deemed necessary, by field inspection as specified under section A.3.6.1.

\section{A.3.7.2 Commentary}

This criterion attempts to eliminate, or at least limit, those loading situations for which the guardrail was not designed.

\section{A.4 Definitions}

Anchorage - component of guardrail used for securing guardrail system to a foundation. Basic Loads - types of loads and their intensities in terms of which design loads are specified.

Component - unit used in assembly of guardrail system.

Connection - component of guardrail system used for attachment of guardrail elements.

Design Loads - specified combinations of basic loads used in the design of guardrail systems and their foundations.

Element - component or structural unit of guardrail system other than connection or anchorage.

Foundation - component of a structure providing support to guardrail system.

Guardrail - same as "Guardrail System."

Guardrail System - structural system serving the function of impeding accidental or inadvertant passage of humans and objects between two adjoining areas it separates.

Midrail - longitudinal element located at intermediate level between top of guardrail and floor.

Structural Systems - assembly of components serving a structural function.

Subsystem - assembly of portion of guardrail system consisting of more than one element and one or more connections and/or anchorages.

System - assembly of components serving a specified function. Same as "guardrail system" unless specified otherwise.

Toprail - longitudinal element located at top of guardrail.

Tread Surface - working surface adjacent to guardrail. 


\section{A.5 References in Model Performance Standard}

A.1 Building Code Requirements for Minimum Design Loads in Buildings and Other Structures, ANSI A58.1-1972, American National Standards Institute, New York, New York, 1972.

A.2 Thom, H.C.S., New Distributions of Extreme Winds in the United States, Proceedings, Journal of the Structural Division, American Society of Civil Engineers, New York, New York, July, 1968.

A.3 Manual of Steel Construction, American Institute of Steel Construction, Inc., 101 Park Avenue, New York, New York 10017, 1973.

A.4 Aluminum Construction Manual, Specifications for Aluminum Structures, The Aluminum Association, 420 Lexington Avenue, New York, New York 10017, November, 1967.

A.5 Building Code Requirements for Reinforced Concrete, ACI 318-71, American Concrete Institute, Detroit, Michigan, 1971.

A.6 Building Code Requirements for Masonry, ANSI A41.1-1953 American National Standards Institute, New York, New York, 1970.

A.7 Building Code Requirements for Reinforced Masonry, ANSI A41.2-1960, American National Standards Institute, New York, New York, 1970.

A. 8 National Design Specification for Stress-Grade Lumber and Its Fastenings, National Forest Products Association, Washington, D.C., 1973.

A.9 Newmark, N.M., and Hall, W.J., Procedures and Criteria for Earthquake Resistant Design, Workshop Proceedings on Building Practices for Disaster Mitigation, Wright, R., Kramer, S., and Culver, C., Editors, BSS-46, Building Science Series, National Bureau of Standards, Washington, D.C., February, 1973.

A.10 Diffrient, Niels, Tilley, Alvin R., and Bardagjy, Joan C., Humanscale 1/2/3, the MIT Press, Massachusetts Institute of Technology, Cambridge, Massachusetts, 1974.

A.11 Synthetic Skins for Automotive Testing, SAE J202, SAE Handbook, Vo1. II, Society of Automotive Engineers, Inc., 1975.

A.12 Woodson, Wesley E., and Conover, Donald N., Human Engineering Guide for Equipment Designers, Second Edition, University of California Press, Berkeley, California, 1973.

A.13 Safety Color Code for Marking Physical Hazards, ANSI Z53.1-1971, American Nationa1 Standards Institute, New York, New York, 1971. 


\section{B.1 Examples of Standard Guardrail Designs}

This section presents numerical illustrations of standard design conforming with provisions of the foregoing Criteria. Included are designs of guardrails consisting of (a) nominal $2 \times 4$ wood sections (figure B.1), (b) aluminum pipe sections (figure B.2), and (c) single standard size steel angles (figure B.3).

The standard guardrail used in these illustrations consists of a top rail, intermediate rail and two posts anchored to the floor but not bullt continuous with the rails. This configuration produces conservative designs since no advantage is taken of the continuities between adjoining spans of systems with more than two posts. In each of the examples, the members are proportioned using the 300-1b (1335-N) concentrated accidental load (A) specified in Criterion A.2.1 for tributary areas equal to or greater than 36 in $(91.4 \mathrm{~cm})$ in width. The direction of this load is governed by the most critical stress condition it produces in the individual elements. The maximum deflections under a load of $1.5 \mathrm{~A}$ are calculated and compared with the values stipulated in Criterion A.2.5.

The use of section standardization throughout a particular type of guardrail installation is usually governed by economic considerations and local availability of common stock items. The sizes used in these examples have been selected arbitrarily and therefore, are not necessarily those most readily available. 
Wood Guardrail System

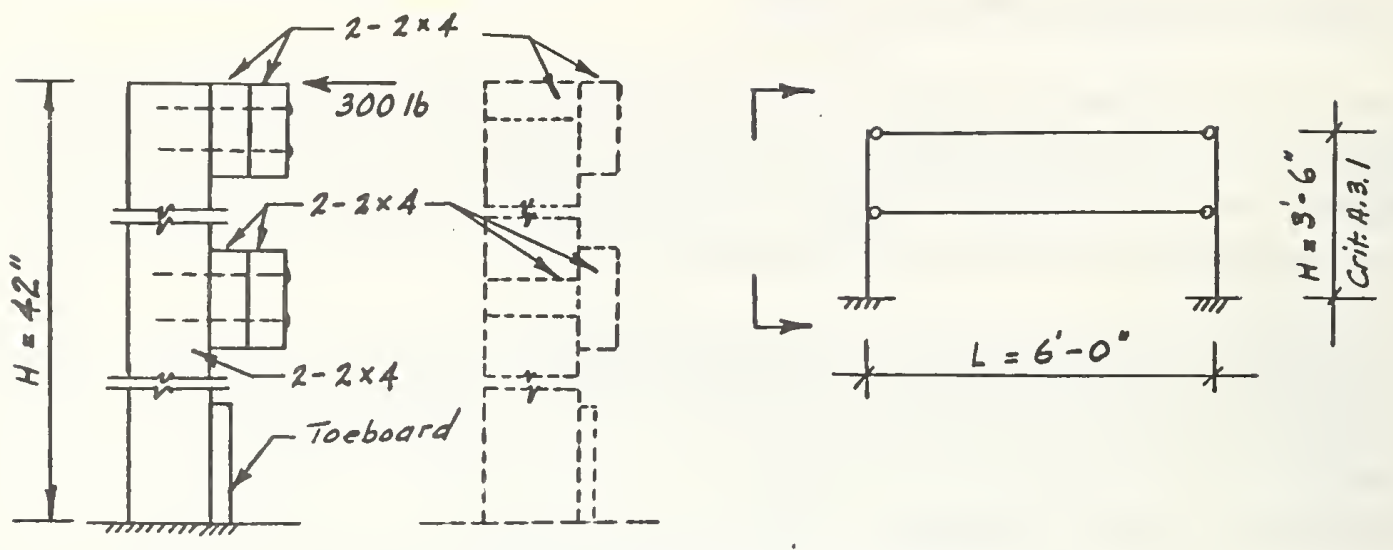

(a)

(b) - Alternative scheme

Design Conditions

- Two posts + top rail + midrail

- Posts fixed at base, rails simply supported

- Southern pine, construction grade (19\% max. m.c.)

- 30016 accidental load (A).

Reference NFPA table I

Top Mid Rails

Assume $L=6^{\prime} \cdot 0^{\prime \prime}, \quad M=P L / 4=300(72) / 4=5400 \mathrm{in}-16$ $F_{b}=1050 \times 2$ (impact) $\times 1.1=2310$ psi.

Try 2-2x4, Layout (a) above

Sreq'd, $=M / F_{b}=5400 / 2310=2.34 \mathrm{in}^{3}$

Assume no integral action betw. $2 \times 4$ 's (conserv.)

$S_{\text {suppld. }}=2^{\text {No. }}(1.5)^{2}(3.5) / 6=2.62 \mathrm{in}^{3}>2.34 \mathrm{in}^{3} \underline{\underline{O K}}$

Check for 30016 acting downward

Ssuppld. $=1.5(3.5)^{2} / 6=3.06 \mathrm{in}^{3}>2.34 \mathrm{in}^{3} \underline{\underline{\text { OKE}}}$

Posts

$M=P H=300(42)=12,600 \mathrm{in}-16$

Sreqd $=M / F_{b}=12,600 /(1050)(2)=6.0 \mathrm{in}^{3}$

Ssupplid $=2^{\text {No. }}(1.5)(3.5)^{2} / 6=6.12 \mathrm{in}^{2}>6.0 \mathrm{in}^{3}$ OK

\{NFPA table l,

footnote 4 !

figure $\mathrm{H}-1$

Check Deflection

$I_{\text {rail }}=2^{N 0} \cdot(3.5)(1.5)^{3} / 12=1.97 \mathrm{in}^{4}, \quad I_{\text {post }}=(3)(3.5)^{3} / 12=10.7 \mathrm{in}$ $\Delta$ rail $=P L^{3} / 48 E I=(300 \times 1.5)(72)^{3} / 48\left(1.4^{6}\right)(1.97)=1.27 \mathrm{in}$ $\Delta$ post $=(P / 2) H^{3} / 3 E I=225(42)^{3} / 3\left(1.4^{16}\right)(10.7)=0.37 \mathrm{in}$

$\Delta_{\text {total }}=1.27+.37=1.64$ in $<4$ in allow. OK …. Crit. A.2.5

Figure B.1 Design of wood guardrail system

NFPA table 1 ? figure $H-l$

Crit. A.2.5 
Design Conditions

- Two posts + Top Rail + Mid Rail

- Posts Fixed, Rails simply Supported

- No welds

- Use 6063-T6 Pipe (40 schedule):

Reference

$$
\begin{aligned}
& F_{t y}=25 \mathrm{ksi}, \quad F_{t u}=30 \mathrm{ksi} \\
& \text { ACMT Table 3.3.1a } \\
& n_{y}=1.65, \quad n_{u}=1.95 . \\
& f_{62}=1.24 f_{t u} / n_{u}=1.24(30) / 1.95=19.08 \text { (tot govern) } \\
& \text { ACM Table 3,3,3 }
\end{aligned}
$$

$$
\begin{aligned}
& M_{L / 2}=300^{3}(6 \times / 2) / 4=5400 \mathrm{in}-16 \\
& S_{\text {read, }}=M / F=5400 / 17,730=0.305 \mathrm{in}^{3}
\end{aligned}
$$

Use Nominal I/2 $\phi$ pipe (Schedule 40) Top st Mid rall

$$
\begin{aligned}
& \text { Most }=300(42)=12,600 \mathrm{im}-16 \\
& \text { Sreqd }=12600 / 17730=0.710 \mathrm{in}^{3}
\end{aligned}
$$

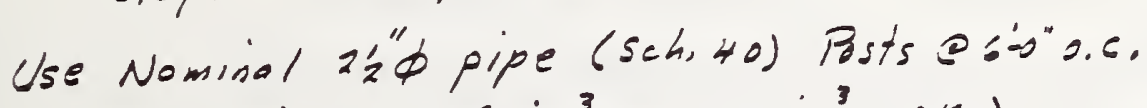

(Ssupplica $=1.06 \mathrm{im}^{3} \approx 0.710 \mathrm{im}^{3} \mathrm{ger}$ )

Max, Deflections:

$$
\begin{aligned}
& I_{\text {resin }}=0.310 \mathrm{in}, \quad I_{\text {post }}=0.666 \mathrm{im} 4 \\
& \Delta_{\text {rail }}=\frac{P L^{3}}{4 B E I}=\frac{(450)(72)^{3}}{48(10.16)(.310)}=1.12^{\prime \prime} \\
& \Delta \text { post }=\frac{(7 / 2) H^{3}}{3 E I}=\frac{(225)(42)^{3}}{3\left(10.1^{16}\right)(.666)}=0.83^{\prime \prime} \\
& \Delta_{\text {TOT. }}=1.95^{\prime \prime} \\
& \left(<4^{\prime \prime}\right. \text { allowed, i OK) Crit, Gia.s) }
\end{aligned}
$$

Figure B.2 Design of aluminum pipe guardrail system

25 
A. $\mathrm{L}$ sing Angle sections.

Design Top Mid Rails:

Try $1-212 \times 22 \times 3_{B}<$, A36 steel

$W t .=5.916 / f t$

$A=1.73 \mathrm{in}^{2}, r_{z}=.487^{\prime \prime}, r_{z}=A r_{z}^{2}=.410 \mathrm{in}^{4}$

$S_{\text {tens, }}=.410 \% .955=.429, S_{\text {compro }}=.41 / 1.078=.380^{\circ}{ }^{4}($ min. $)$ Use $L=8^{\prime}=96^{\prime \prime}, M_{L / 2}=300$ (96) $/ 4=7200$ in -16 $f=M / s_{\min }=7200 \% 38=18,950$ psi $<22,000$ psi OK

Design of Posts:

$M=300(42)=12,600 \mathrm{in}-16, I_{x}=.984 \mathrm{~m}^{4}$

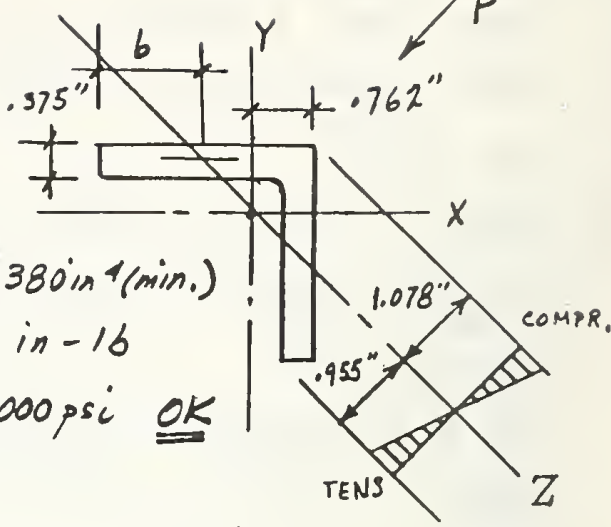

$S_{\text {tens, }}=.784 / .762=1.29 \mathrm{in}^{3}, S_{\text {coxpl, }}=.984 / 1.738=.56$ in $^{3}($ mind. $)$

$6=1.738^{\prime \prime}, \quad b / t=1.738 / .375=4.63$

$76 / \sqrt{F_{y}}=76 / \sqrt{36}=12.7 \gg b / t$, wan OKL (Alsc 1.9.1.2 \&APP,C)

$f_{b}=M / s_{\text {min }}=12600 / .566=22,261 \approx 22,900$ allow, OK

Check $M_{\text {wt. }}=5.9(8)^{2}(12) / 8=566,4$ in -16

DL: ${ }_{T_{D C}}=M / S_{\text {(tens.) }}=\$ 66.4 / 1.29=439 \mathrm{ps}^{\prime}$

$\therefore T_{6}($ cowinied $)=18990+439=19,290<2 \approx$, 200 O1c

$\therefore$ Use $2 \frac{1}{2} \times 2^{\prime} 2 \times 3<$ fer all meners

Check Deflections:

Top rail, e z-axis:

$P=450^{\circ} \& L / 2, \theta=45^{\circ}$

$\Delta_{z}=\frac{450(96)^{3}}{48\left(29^{16}\right)(.410)}=0.70 \mathrm{in}$

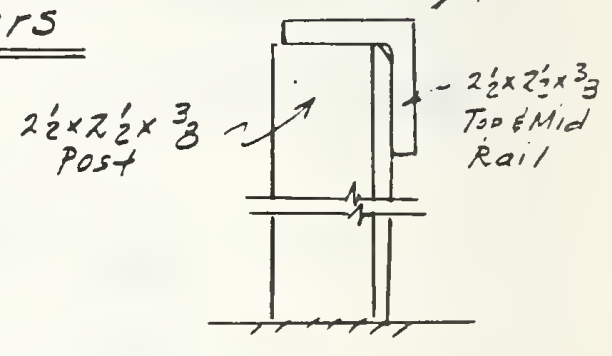

Post lo: i: $\quad 0.5 P / \sqrt{2}=450(.5) / \sqrt{2}=1.9+$

$\Delta_{x}=\frac{P H^{3}}{3 E I_{x}}=\frac{159(42)^{3}}{3\left(29^{16}\right)(.984)}=0.21 \mathrm{in}$

$\left.\Delta=\{[.70 / \sqrt{2})+.21]^{2}+[.70]^{2}\right\}^{1 / 2}=.99^{\prime \prime}$

$\ll 4^{\prime \prime}$ allowed, way ok

B. Using steel Pipe

Calculations similar to fig. B.Z lead to following sections:

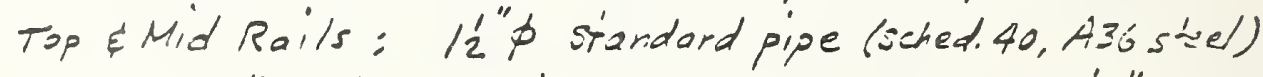

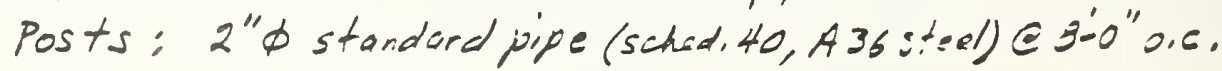

Figure B.3 Design of steel guardrail systems 
NBS.114A (REV. 7-73)

\begin{tabular}{|c|c|c|}
\hline $\begin{array}{l}\text { 1. IPIIBI.ICATION OR IRIOYORT NO. } \\
\text { NBSIR 76-1131 }\end{array}$ & $\begin{array}{l}\text { 2. (inv't Accession } \\
\text { No. }\end{array}$ & 3. Recipicent's Accession No. \\
\hline \multicolumn{2}{|l|}{ 4. TITI.E AND SUIBTITL.I: } & $\begin{array}{r}\text { 5. Publication Datc } \\
\text { July } 1976\end{array}$ \\
\hline \multicolumn{2}{|l|}{ A Model Performance Standard for Guardrails } & 6. Performing Organization Cods \\
\hline $\begin{array}{l}\text { 7. AUTHOR(S) } \\
\text { S.F. Fattal; L.E. Cattaneo; G.E. Turner and S. }\end{array}$ & Robinson & 8. Performing Organ. Report No. \\
\hline \multirow{2}{*}{\multicolumn{2}{|c|}{$\begin{array}{l}\text { 9. PERFORMING ORGANIZATION NAME AND ADDRESS } \\
\text { NATIONAL BUREAU OF ST ANDARDS } \\
\text { DEPARTMENT OF COMMERCE } \\
\text { WASHINGTON, D.C. } 20234\end{array}$}} & $\begin{array}{l}\text { 10. Project/Task/Work Unit No. } \\
4612471\end{array}$ \\
\hline & & 11. Contract/Grant No. \\
\hline \multirow{2}{*}{\multicolumn{2}{|c|}{$\begin{array}{l}\text { 12. Sponsoring Organization Name and Complete Address (Street, City, State, ZIP) } \\
\text { Occupational Safety and Health Administration } \\
\text { Department of Labor } \\
\text { Washington, D.C. } 20210\end{array}$}} & $\begin{array}{l}\text { 13. Type of Report \& Period } \\
\text { Covered } \\
\text { Fina1. Report }\end{array}$ \\
\hline & & 14. Sponsoring Agency Code \\
\hline
\end{tabular}

\section{SUPPI.EMENTARY NOTES}

NBSIR to sponsor to be incorporated in BSS Report containing analysis of experimental data basis; and augmented by NBSIR containing additional background material.

16. ABSTRACT (A 200-word or less factual summary of most significant information. If document includes a significant bibliography or literature survey, mention it here.)

A model performance standard and design illustrations are presented for the design, construction and evaluation of guardrail systems, which vill be used for the protection of employees against occupational hazards. The standard stipulates both structural and non-structural safety requirements. Each criterion includes a commentary section describing the rationale used in its formulation. This rationale is for the most part, based on independent experimental and analytical research investigations conducted at NBS in behalf of OSHA.

17. KEY WORDS (six to twelve entries; alphabetical order; capitalize only the first letter of the first key word unless a proper name; separated by semicolons) Design; dynamic loads; guardrails; industrial accidents; non-structural safety; occupational hazards; performance standard; personnel railings; personnel safety; static loads; stiffness; structural safety.

\begin{tabular}{|c|c|c|}
\hline 18. AVAILABILITY X Unlimited & $\begin{array}{l}\text { 19. SECURITY CLASS } \\
\text { (THIS REPURT) }\end{array}$ & 21. NO. OF PAGES \\
\hline [- For Official Distribution. Do Not Release to NTIS & UNCL ASSIF 1ED & \\
\hline $\begin{array}{l}\text { Order From Sup. of Doc., U.S. Government Printing Office } \\
\text { Washington, D.C. 20402, SD Cat. No.C } 13\end{array}$ & $\begin{array}{l}\text { 20. SECURITY CLASS } \\
\text { (THIS PAGE) }\end{array}$ & 22. Price \\
\hline $\begin{array}{l}\text { X Order From National Technical Information Servicc (NTIS) } \\
\text { Springfield, Virginia } 22151\end{array}$ & UNCLASSIFIED & \\
\hline
\end{tabular}




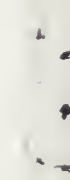


